\title{
ANALYSIS OF THE IMPACT OF DOUBLE SHOT PEENING ON THE VALUE OF ROUGHNESS PARAMETER AND DISTRIBUTION OF STRESSES IN THE RSA 501 ALLOY
}

\author{
Paulina Byczkowska', Jacek Sawicki', Bartłomiej Januszewicz'1, Mariusz Stegliński' \\ 1 Instutute of Materials Science and Engineering, Lodz University of Technology, Stefanowskiego 1/15, 90-924 \\ Lodz, Poland, e-mail: paulina.byczkowska@p.lodz.pl
}

Received: 2017.05.15

Accepted: 2017.08.01

Published: 2017.09.03

\begin{abstract}
The bead blasting process is widespread in both the automotive and aerospace industry and is performed in order to improve the fatigue strength of various components. Bead blasting is a cold plastic forming process during which the surface of the material processed is hit by small, hard particles consisting of steel pellets, bearing balls or glass beads. It increases the hardness of the outer layer and establishes compression stresses inside it, which is why this processing is often used to improve fatigue strength. Contrary to other peening methods, bead blasting does not result in a reduction in the height of the processed surface's unevenness in most cases. Shot peening changes the residual tensile stresses into residual compression stresses, thanks to which, the lifetime of the parts processed is extended and their carrying capacity is increased.

The double shot peening process proposed by the authors consists in a two-stage bead blasting process. The first stage consists in blasting with round cast steel pellets, pellets cut from wire or cast iron pellets. During the second stage the same samples underwent glass bead blasting. The tests conducted on the RSA-501 aluminum alloy indicate that as a result of the processing medium's impact in the form of glass beads or pellets of different diameter and shape, a permanent plastic deformation of the material surface occurs. On the basis of the obtained results it is possible to infer that the choice of parameters of both conventional shot peening and the double shot peening determine the impact thereof on the material's mechanical properties. Thanks to the application of the double shot peening process there is a noticeable decrease in value of the Ra parameter, by about $40 \%$ on average. When analyzing the compressive stress results it is possible to state that after the first blasting process the value of stress was increasing when moving deeply into the sample from its surface, while after the glass bead blasting the value of compressive stress was significantly higher already near the surface. Double shot peening results in an increase in the value of compressive stresses by $40-50 \%$ when compared to conventional blasting.
\end{abstract}

Keywords: shot peening, double shot peening, surface treatment, residual stresses, roughness.

\section{INTRODUCTION}

Industrial branches like the automotive and aerospace industry put great efforts into reducing production costs together with increasing the strength properties of components $[1,8]$. So the trend is to replace the heavy parts with some another material such as light alloys [7, 14]. The problem with these alloys is their poor mechanical properties. Thus, there is a need for some enhancement, which could be accomplished, among other ways, by a surface treatment technique called shot peening. 
Shot peening results in an increase in the hardness of the outer layer and establishes compression stresses inside it, which is why this processing is often used to improve fatigue strength $[2,3,5,6,10]$. This process was considered favorable even after a three-stage low cycle bend test [13]. The compression stresses prevent the propagation of cracks since they are unable to spread in a compressed environment [5]. Contrary to other peening methods, shot peening usually results in an increase in the roughness of the processed surface [4].

Double shot peening (duplex SP), that is two-stage shot peening, is an improvement of the conventional shot peening method. The first stage takes place according to conventional blasting methods, while during the second stage the blasting takes place with the use of steel or glass beads of very small diameter (about $0.1 \mathrm{~mm}$ ). Conventional shot peening enables compression stresses to be introduced relatively deep below the surface, while the double shot peening results additionally in an increase in value of these stresses. This enables fatigue strength to be increased considerably, by about 1.5 times in comparison to a conventional process [9]. Additionally, double shot peening results in a smoothing of the surface, that is, reducing the roughness parameter, which has a significant impact on the tribologic properties of such a surface.

In this paper there is presented the impact of applying conventional abrasive blasting processing and double shoot peening on the value of roughness and the distribution of residual stresses in the outer layer of the experimental aluminum alloy, the trade name of which is RSA 501.

\section{EXPERIMENTAL SECTION}

\section{Test Material}

An experimental aluminum alloy was used in the tests that goes by the trade name of RSA 501, which has the following chemical composition: $\mathrm{Al} \mathrm{Mg} 5 \mathrm{Mn} 1 \mathrm{Sc} 0.8 \mathrm{Zr} 0.4$ and properties specified in Table 1.

In total, 8 samples made of RSA 501 aluminum alloy were tested. The samples were obtained by cutting a rod with a diameter of $\phi$ $50 \mathrm{~mm}$. Afterwards the samples were ground using sand paper with an abrasive grade from 250 to 800 . The value of the roughness parameter prior to the shot peening process amounted to $\mathrm{Ra}=0.04 \mu \mathrm{m}$. The samples were subjected in sequence to the annealing process at a temperature of $500^{\circ} \mathrm{C}$ for $4 \mathrm{~h}$. Next they were subjected to abrasive blasting for $24 \mathrm{~h}$. After another $24 \mathrm{~h}$ a stress measurement was conducted.

\section{Testing Methods}

The experiment consisted in conducting shot peening processing with the use of various peening media. The conventional shot peening was carried out for four kinds of strengthening media made of various materials and with different diameters and shapes. For conducting the bead blasting process the following were used (Tab. 2):

- round cast steel pellets with a diameter of 0.5 $\mathrm{mm}$ (designation according to FEPA standard: S230), $1.8 \mathrm{~mm}$ (S390),

- pellets cut from wire with a diameter of $1.4 \mathrm{~mm}$,

- glass beads with a diameter of 0.6-0.8 mm.

Next to pellet type and granulation, another variable was also the value of pressure applied.

Table 1. Properties of RSA-501 [12]

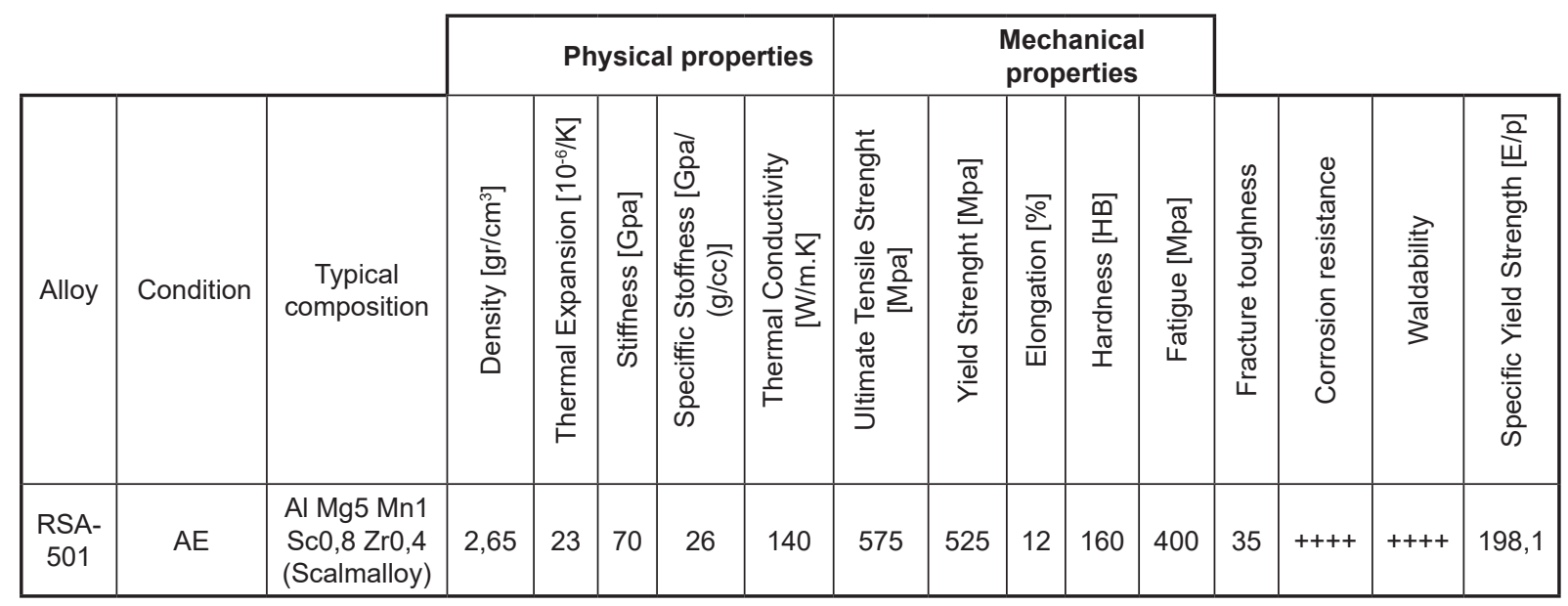


Table 2. Bead blasting process parameters

\begin{tabular}{|c|c|c|c|c|c|c|}
\hline \multirow{3}{*}{$\begin{array}{l}\text { Sample } \\
\text { number }\end{array}$} & \multicolumn{4}{|c|}{ Type of shot } & \multirow{2}{*}{\multicolumn{2}{|c|}{ Pressure }} \\
\hline & \multicolumn{2}{|c|}{ Steel shot } & \multirow{2}{*}{$\begin{array}{c}\text { Cut wire steel shot } \\
1,4 \mathrm{~mm}\end{array}$} & \multirow{2}{*}{$\begin{array}{c}\text { Glass microbeads } \\
\varepsilon\end{array}$} & & \\
\hline & $0,5 \mathrm{~mm}$ & $1,8 \mathrm{~mm}$ & & & 3 bar & $7 \mathrm{bar}$ \\
\hline 1 & $x$ & & & ర్ & & $x$ \\
\hline 2 & $x$ & & & $\overline{\bar{\sigma}}$ & $x$ & \\
\hline 3 & & $x$ & & 0 & & $x$ \\
\hline 4 & & $x$ & & $\frac{5}{3}$ & $x$ & \\
\hline 5 & & & $x$ & $\begin{array}{l}0 \\
\infty \\
1 \\
0\end{array}$ & & $x$ \\
\hline 6 & & & $x$ & 8 & $x$ & \\
\hline
\end{tabular}

The distance from the nozzle to the sample was $150 \mathrm{~mm}$. The pellet angle of incidence was constant and was $90^{\circ}$.

After carrying out a conventional bead blasting process and tests of roughness and stresses, the samples were subjected to a double shot peening process. The double shot peening process consisted of a two-stage bead blasting process.

Table 3. Parameters of roughness measurement carried out using a Hommel-Etamic T8000 profilometer

\begin{tabular}{|c|c|}
\hline \multicolumn{2}{|c|}{ Roughness measurement parameters } \\
\hline Scope of measurement & $80 \mu \mathrm{m}$ \\
\hline Direction of measurement & From left to right \\
\hline Spacing between points & $0.5 \mu \mathrm{m}$ \\
\hline Tip radius & $0.005 \mathrm{~mm}$ \\
\hline Tip type & $\mathrm{T} 1$ \\
\hline
\end{tabular}

The first stage consists in blasting with round cast steel pellets or pellets cut from wire. Next bead blasting using glass beads was carried out and with the application of the following parameters: pressure - 3 bar, distance from nozzle - 150 $\mathrm{mm}$. The conventional bead blasting process and double shot peening process were carried out in a pneumatic injector sand blasting cabin of the CONTRACOR brand.

\section{Roughness Test Results}

Surface roughness was measured using a Hommel - Etamic T8000 profilometer with EVOVIS 2.0 software and the assumed parameters presented in Table 3 (Filter ISO 4287:ISO 11562).

On all the samples prior to processing the roughness parameter obtained was $\mathrm{Ra}=0.04 \mu \mathrm{m}$. The results within the scope of changes in $\mathrm{Ra}$ as

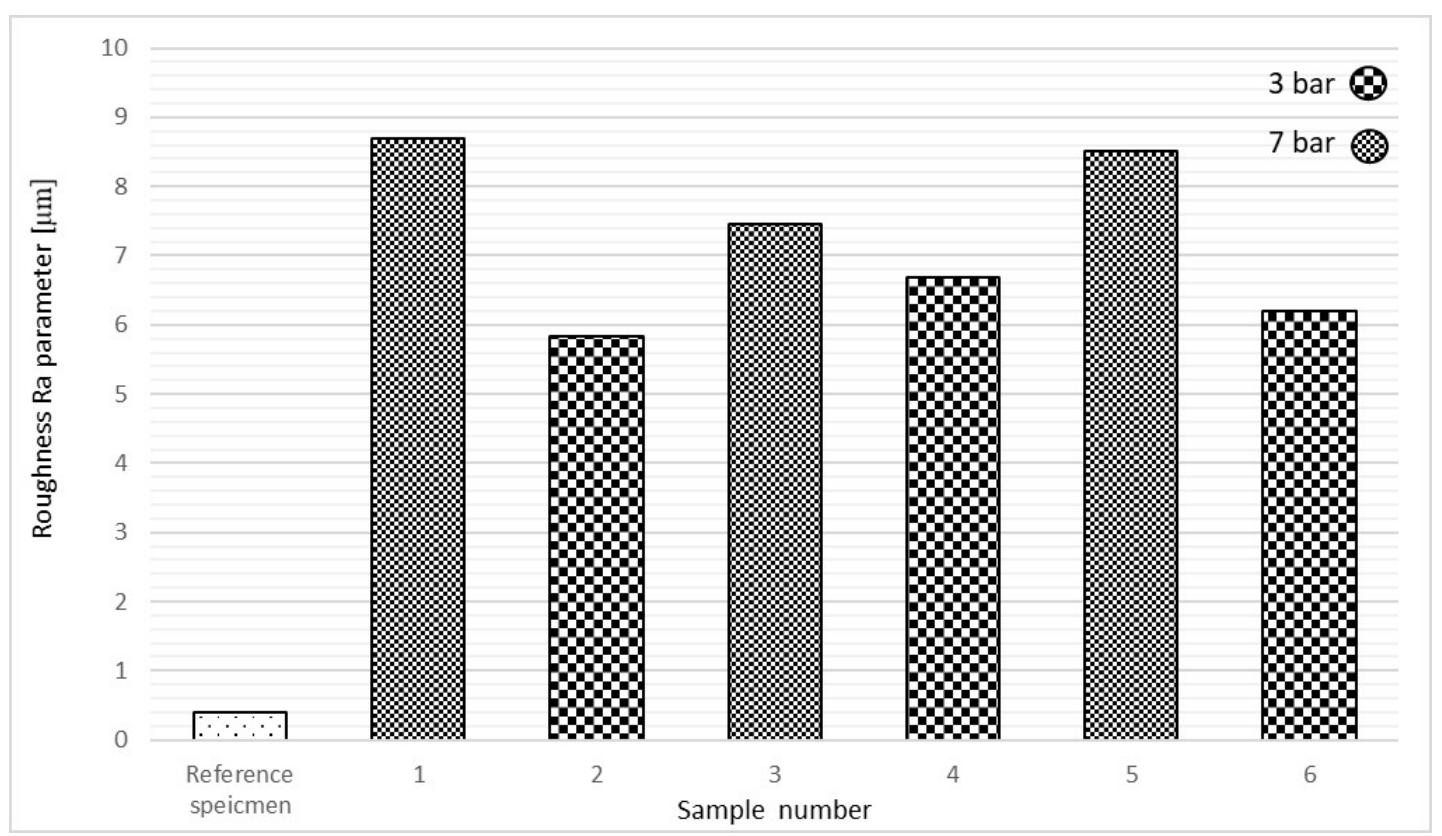

Fig. 1. Values of the Ra parameter for 3 and 7 bar and $150 \mathrm{~mm}$ distance from nozzle 
a function of the pressure distance applied and diameter of the medium are presented in the form of bar graphs in Figures 1-4.

\section{Values of Ra parameter dependent on the shot peening process parameters}

Figure 1 presents the impact of the peening medium used and the change in nozzle working pressure on the change in Ra roughness parameter for the conventional peening process. As a result of the deformation of samples by means of various blasting agents significantly increased surface roughness was obtained.

The size of pellets has a significant impact on the roughness parameter. A tendency for the Ra roughness parameter to increase together with an increase in working pressure of the nozzle was also observed. The lowest Ra roughness value was obtained for sample $2(0.5 \mathrm{~mm}$ round cast steel pellets) with a 3-bar application pressure.

In spite of large differences in the size and shape of pellet (samples 1 and 5) a very similar value of the Ra parameter is noticeable. It may be caused by the same development of surface.

\section{Roughness results after glass bead blasting}

In order to carry out the double shop peening process, during the first stage the same processing medium as in case of conventional processing was used and during the second stage the process- ing medium applied were glass beads $\phi 0.6-0.8$ $\mathrm{mm}$, with the following parameters: a pressure of 3 bar and a distance between the nozzle and the sample of $150 \mathrm{~mm}$.

The results of $\mathrm{Ra}$ parameter measurement value after the application of the second medium in the form of glass beads are presented on Figure 2.

What is perfectly visible here is the significant reduction in the value of the roughness parameter after the application of the double shot peening process (Figure 2). This is owing to the activity of glass beads, which smooth the surface processed, resulting in a reduction in roughness. As a result of application of glass bead blasting there is a noticeable decrease in the value of the Ra parameter, by about $40 \%$ on average.

\section{RESULTS OF STRESS MEASUREMENTS}

In order to obtain the distribution of values of residual stresses in the upper layer of aluminum alloy modified through bead blasting, local etching at measurement point was carried out on the samples. For that purpose a 8818 -V3 - PROTO electropolishing machine fitted with a special etching head with constant flow of electrolyte and limitation of the etching area to a circle with diameter of $5 \mathrm{~mm}$ was used. For etching an electrolyte of perchloric acid was used. The current and voltage parameters applied, that is, voltage of $60 \mathrm{~V}$ and a current of $1 \mathrm{~A}$ enabled the

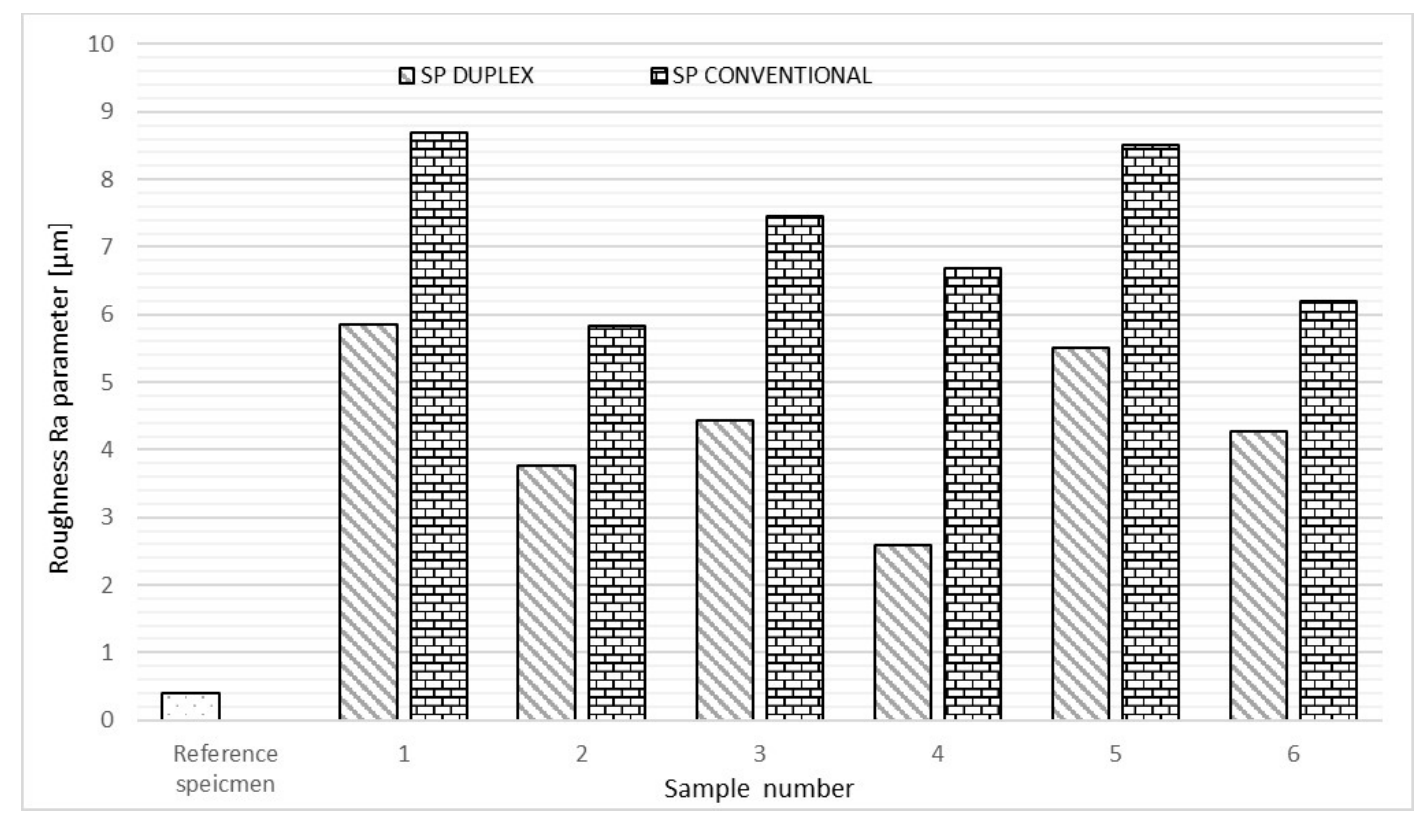

Fig. 2. Comparison of Ra parameter values for conventional peening and double shot peening 
obtainment of a maximum etching rate at the level of 60 micrometers per minute. Down to the depth of 50 micrometers the material was etched every 10 micrometers and a measurement of stresses at the etching point was carried out. Below the depth of 50 micrometers the material was etched every 50 micrometers down to a depth of 250 micrometers.

The measurements of residual stresses were carried out using an X-ray method by means of a PROTO iXRD diffractometer. The test was carried out with the following parameters: Cr lamp, $\mathrm{K} \alpha 1$, lamp voltage of $20 \mathrm{kV}$, lamp current of 4 $\mathrm{mA}$, Bragg angle of $156,31^{\circ}$ (reflections from the 222 family of planes), applied oscillation in relation to the beta angle amounting to $3^{\circ}$, LPA correction and $2 \mathrm{~mm}$ aperture. The location of the diffraction peaks obtained was approximated using the Cauchy function. The spring constants were adopted according to the computer application database: $(1 / 2) \mathrm{S} 2=18,56 \cdot 10-61 / \mathrm{MPa}$ and $\mathrm{S} 1=4.79 \cdot 10-61 / \mathrm{MPa}$. The measurement error is $\pm 5 \mathrm{MPa}$.

The maximum value of compression stresses in the model sample amounted to - $68 \mathrm{MPa}$ and was obtained on the sample surface. The relationship of residual stress values as a function of distance from the surface for conventional bead blasting and double shot peening is presented on Figures 3-8.

\section{Stress results after bead blasting and double shot peening}

A characteristic profile of the relationship of stresses present as a function of distance from the surface for every sample tested was noticed and it is totally different than in the case of the model sample. According to the test results, the maximum compression stresses are present not on the sample surface, as in case of the model sample, but in a certain distance from it. The nature of distribution of residual stresses, as well as their value and location where maximum stresses occur depend, first and foremost, on the pellet type used. However, there seems to be no noticeable impact of the nozzle working pressure on the distribution of stresses. In each of the cases analyzed the distribution of stresses for a given type of pellet and processing is very similar and the maximum differences in distribution do not exceed $30 \%$ of value. The improved zone depth in each of the cases tested exceeded $250 \mu \mathrm{m}$.

The highest values of compression stresses on the surface after the conventional peening process were obtained for the sample no. 3K (about $-80 \mathrm{MPa}$ ). Meanwhile, after the application of double shot peening they were the highest for sample no. 1D (about -90MPa).

In the case of all the samples subjected to double shot peening an increase in the value of

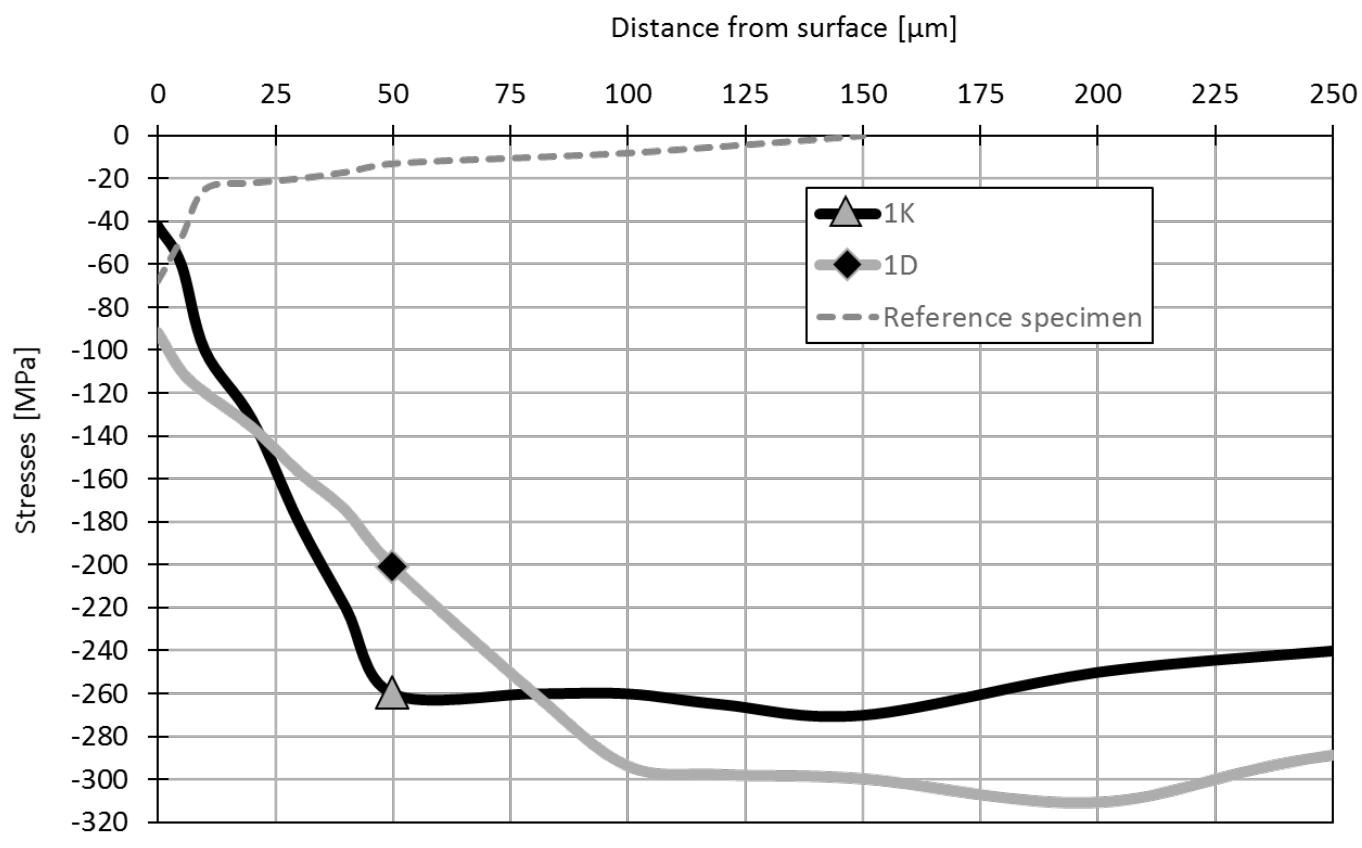

Fig. 3. Distribution of compression stresses after conventional peening (K) and double shot peening (D) for sample no. 1 


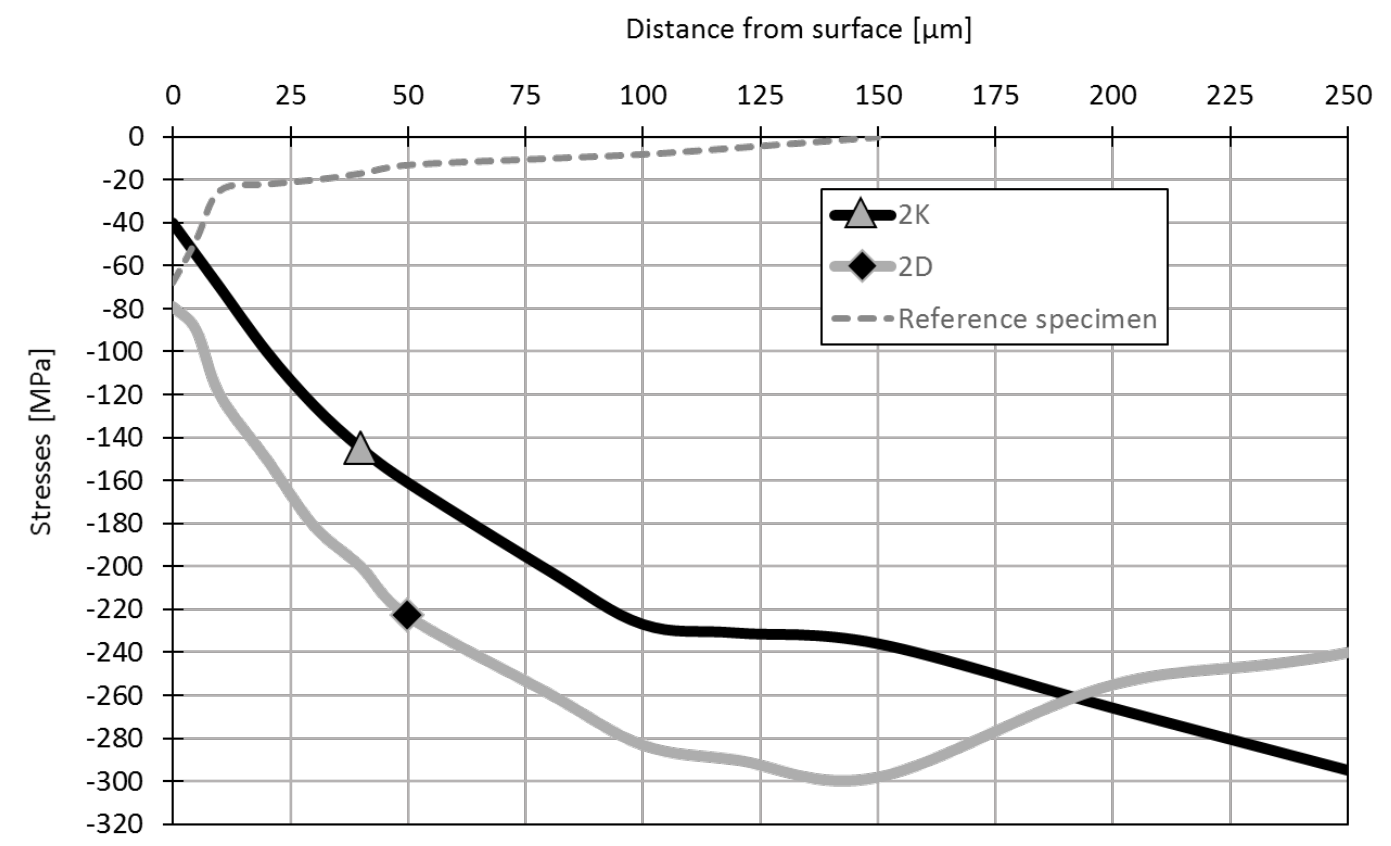

Fig. 4. Distribution of compression stresses after conventional peening (K) and double shot peening (D) for sample no. 2

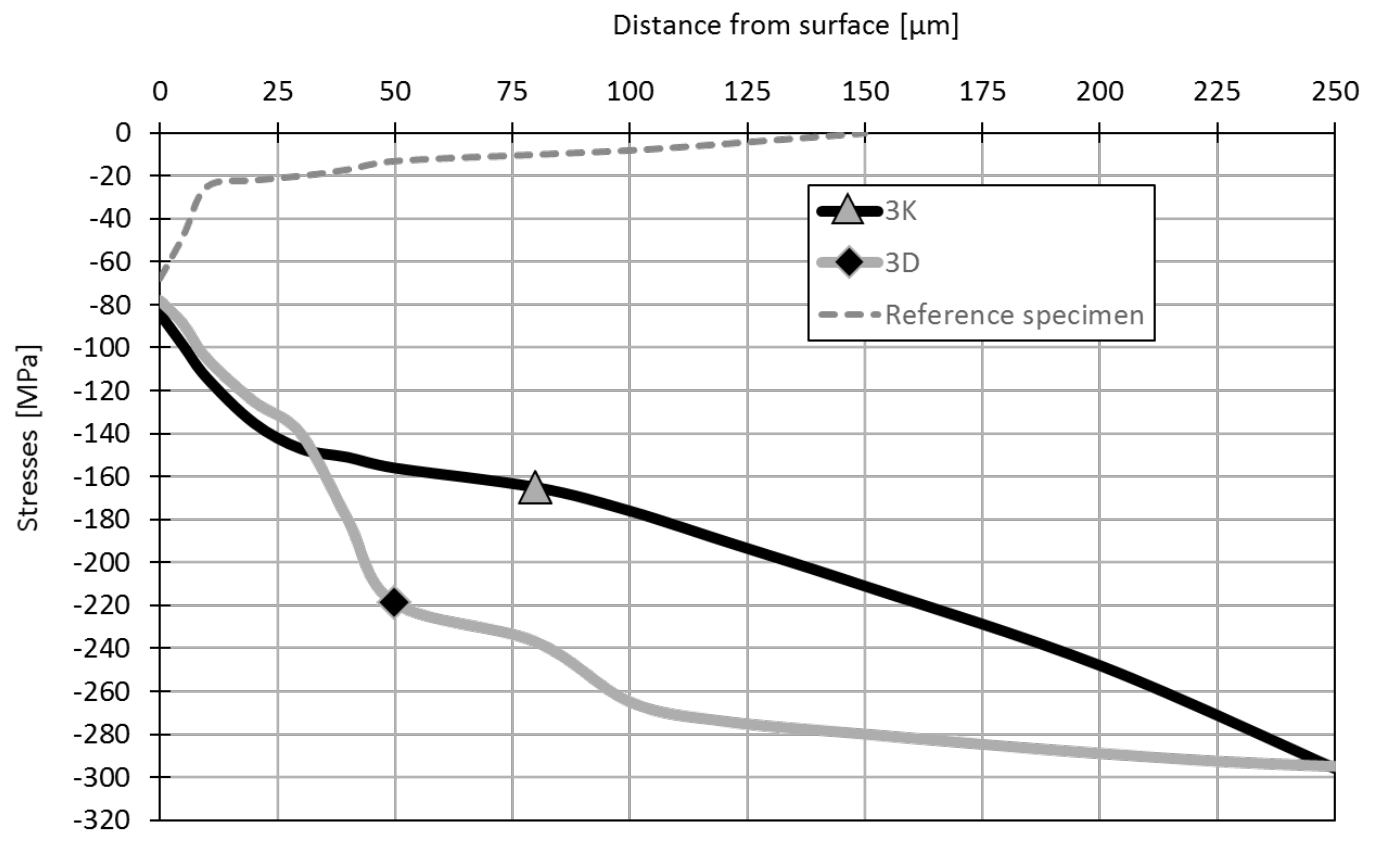

Fig. 5. Distribution of compression stresses after conventional peening $(K)$ and double shot peening (D) for sample no. 3

compressive stresses by $40-50 \%$ was observed when compared to conventional bead/shot blasting. The maximum compression stresses (about -310 MPa) after the double shot peening process were obtained when, during the first stage of processing, $0.5 \mathrm{~mm}$ round cast steel pellets were used at a pressure of 7 bar (sample with number 1D) and $1.4 \mathrm{~mm}$ pellets cut from wire at a pressure of 3 bar (sample no. 6D) at a depth of $200 \mu \mathrm{m}$ from the surface and for the sample that in the first stage was also processed using 0.5 round cast steel pellets, but at a lower pressure - 3 bar - (sample no. 2D) at a depth of $150 \mu \mathrm{m}$. 


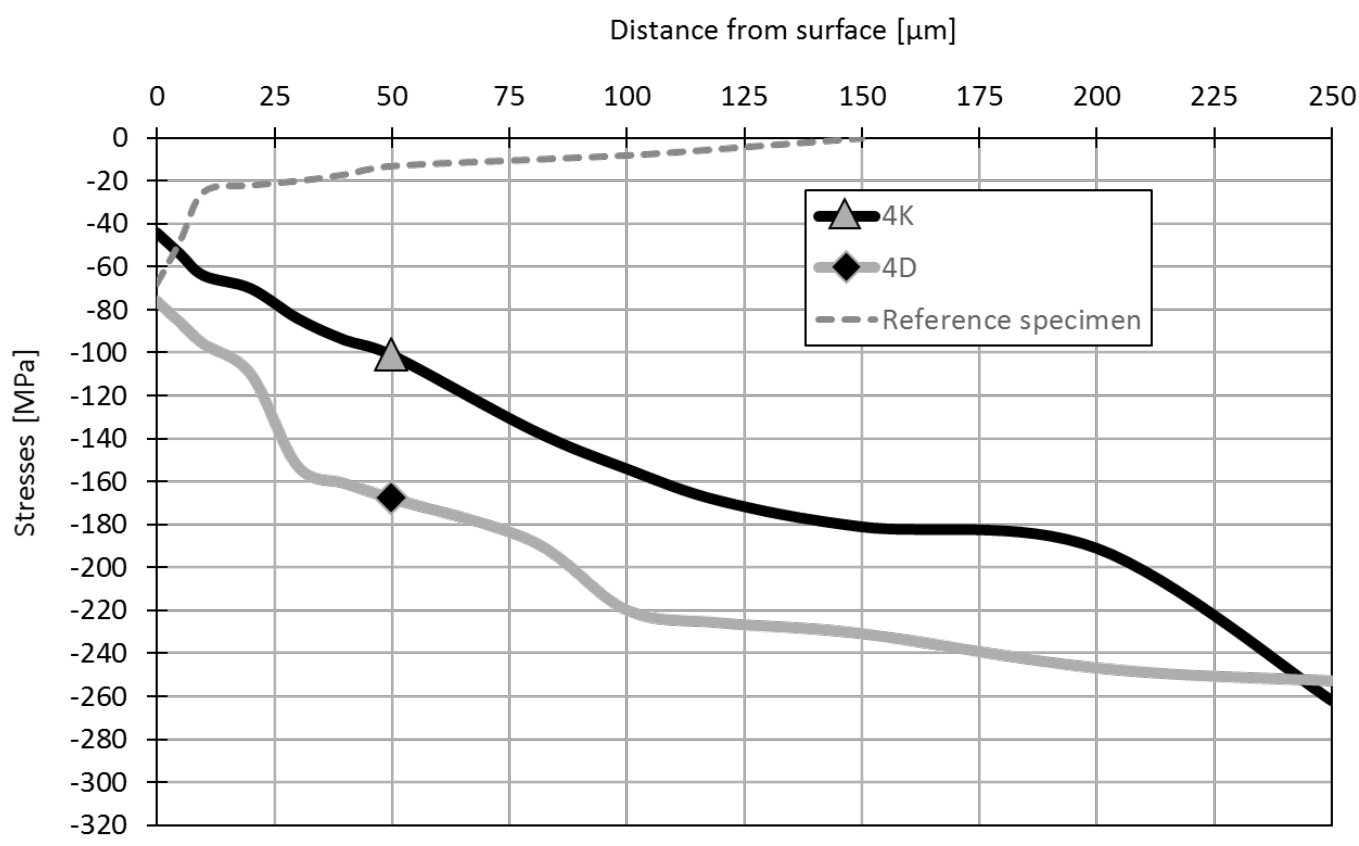

Fig. 6. Distribution of compression stresses after conventional peening $(\mathrm{K})$ and double shot peening (D) for sample no. 4

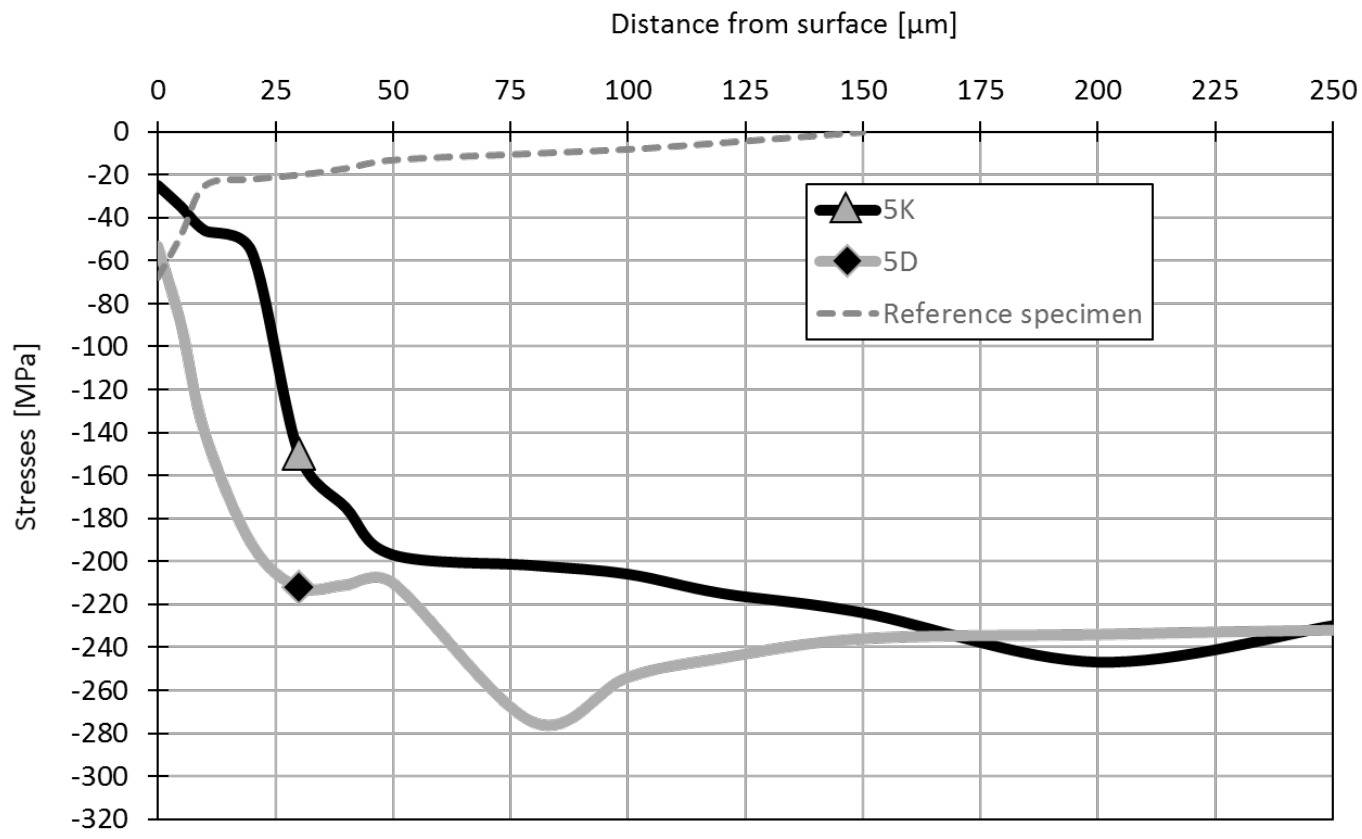

Fig. 7. Distribution of compression stresses after conventional peening $(K)$ and double shot peening (D) for sample no. 5

On Figures 7-8 that present the distribution of residual stresses for the bead blasting process employing cut pellets a distinct plastic strengthening of the samples was noticed. It is noticeable thanks to a characteristic curve of the stress profile at a value of about 25 or $50 \mu \mathrm{m}$ depending on the processing parameters adopted.

\section{CONCLUSIONS AND RECOMMENDATIONS}

The conventional bead blasting process was modified by adding one more stage of blasting. On the samples subjected to double shot peening there is visible significant improvement in the distribution and values of compression stresses. 


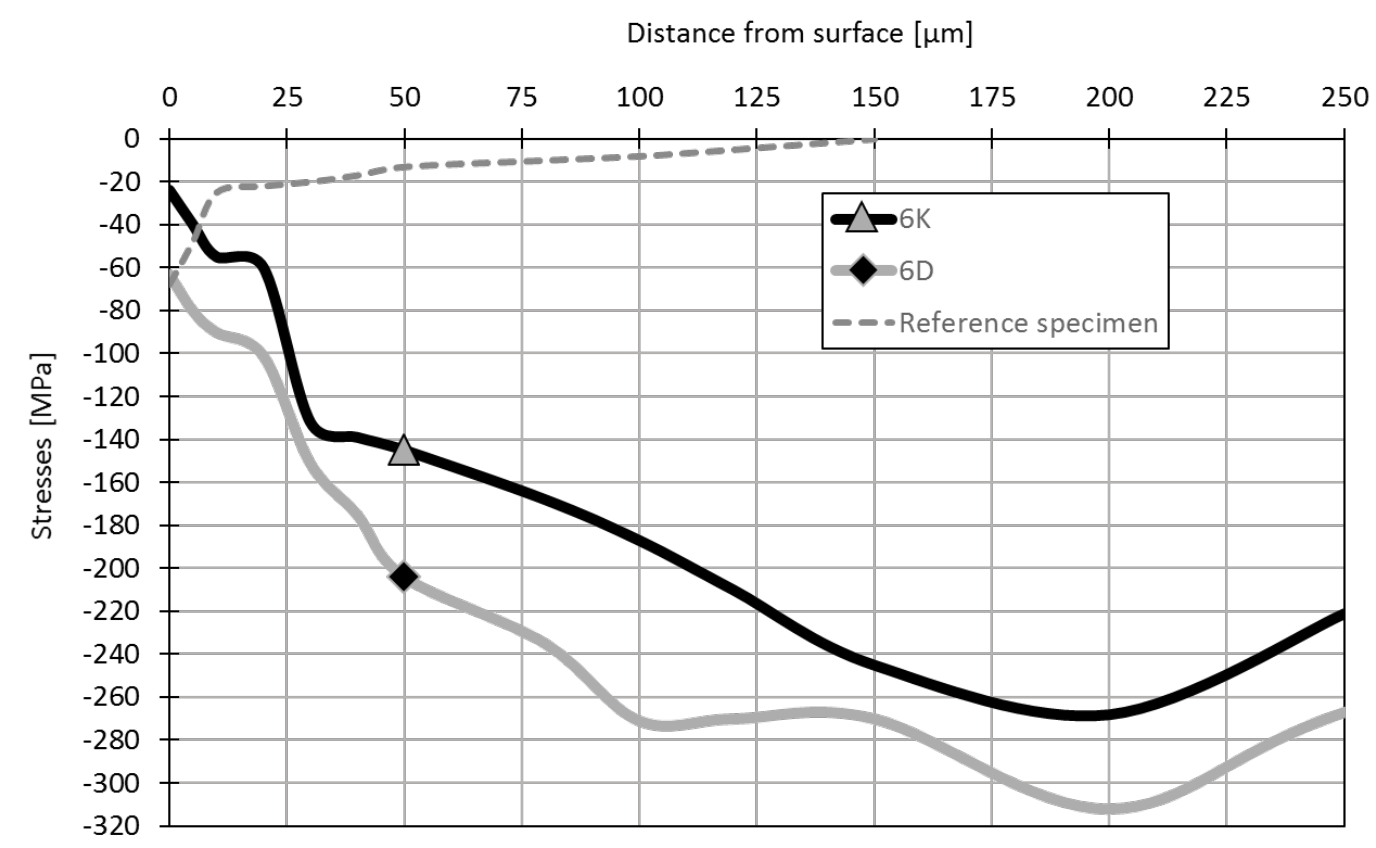

Fig. 8. Distribution of compression stresses after conventional peening (K) and double shot peening (D) for sample no. 6

When analyzing the residual stress results it is possible to state that after the first blasting process the value of compression stress acting from the surface and into the sample was increasing. The glass bead blasting process resulted in a compressive stress distribution achieving significantly higher values, starting from the sample surface.

Conducting conventional bead blasting at a higher pressure results in obtaining a higher value of the roughness parameter. It is noticeable for every kind of pellets used. The application of double shot peening resulted in a reduction of the Ra parameter value by about $40 \%$ on average.

Therefore, it might be a good idea to carry out one more stage with the use of even finer glass beads or so-called glass powder in order to obtain a roughness parameter similar to the initial one $(0.4 \mu \mathrm{m})$.

Double shot peening results in an increase in the value of compressive stresses by $40-50 \%$ when compared to conventional bead/shot blasting. There has not been any noticeable impact of the nozzle working pressure on the distribution of stresses. The type of pellets used has the greatest impact on stress distribution.

The highest values of compression stresses on the surface were obtained for the conventional shot blasting process when using round cast steel pellets with a diameter of $1.8 \mathrm{~mm}$ (sample no. 3K, about -80 MPa). In the case of double shot peening the maximum stress values on the surface were obtained for double shot peening that employed $0.5 \mathrm{~mm}$ round cast steel pellets during the first stage (sample no. 1D, about $-90 \mathrm{MPa}$ ). The location and value of maximum residual stresses is between 100 and $200 \mu \mathrm{m}$ below the surface, depending on the type of pellets.

On the basis of the obtained results it is possible to infer that the choice of parameters of both the conventional shot peening and the double shot peening determine the impact thereof on the material's mechanical properties. It has an impact on, first and foremost, the distribution of compression stresses in the material that result in the enhancement of its durability and improvement in the condition of its surface (roughness), which may contribute to a deterioration of strength-related properties.

We would like to thank the Alumetal-Technik company located in Łódź for performing abrasive blasting on the samples tested.

\section{REFERENCES}

1. Bakalova T., Petkov N., Blažek T., Kejzlar P., Louda P., Voleský L. Influence of parameters of the coating process on the mechanical and tribological properties of the thin films. Defect and Diffusion Forum, 368, 2016, 59-63.

2. Benedetti M., Fontanari V., Scardi P., Ricardo C.L.A., Bandini M. Reverse bending fatigue of 
shot peened 7075-T651 aluminium alloy: The role of residual stress relaxation. International Journal of Fatigue, 31, 2009, 1225-1236.

3. Curtis S., de los Rios E.R., Rodopoulos C.A., Levers A. Analysis of the effects of controlled shot peening on fatigue damage of high strength aluminium alloys. International Journal of Fatigue, 25, 2003, 59-66

4. Dzierwa A., Korzyński M. Badania możliwości poprawy przez kulowanie właściwości zmęczeniowych elementów chromowanych. Archiwum Technologii Maszyn i Automatyzacji, 27 (1), 2007, 121-130.

5. Gawroński Z., Sawicki J. Technological surface layer selection for small module pitches of gear wheels working under cyclic contact loads. Materials Science Forum, 513, 2006, 69-74.

6. Jianming W., Feihong L., Feng Y., Gang Z. Shot peening simulation based on SPH method. The International Journal of Advanced Manufacturing Technology, 56, 2011, 571-578.

7. Kaczmarek Ł., Stegliński M., Świniarski J., Sawicki J., Batory D., Kyzioł K., Kołodziejczyk Ł., Szymański W., Zawadzki P., Kottfer D., Optimization of the heat treatment and tribological properties of 2024 and 7075 aluminium alloys, Archives of Metallurgy and Materials, 58(2), 2013, 535-540.
8. Kaczmarek Ł., Kula P., Sawicki J., Armand S., Castro T., Kruszyński P., Rochel A. New possibilities of applications aluminum alloys in transport. Archives of Metallurgy and Materials, 54, 2009, 1199-1205.

9. Matsumura S., Hamasaka N.; High Strength and Compactness of Gears by WHSP (Double Hard Shot Peening) Technology, 2006.

10. Meguid S.A., Shagal G., Stranart J.C., International Jurnal of Impact Engineering. 27, 119-134 (2002)

11. Rodopoulos C.A., Curtis S.A., de los Rios E.R., Solis Romero J. Optimisation of the fatigue resistance of 2024-T351 aluminium alloys by controlled shot peening-methodology, results and analysis. International Journal of Fatigue, 26, 2004, 849-856.

12. Rsp-technology-online 9-10-2016- http://www. rsp-technology.com/RSP\%20Technology $\% 20$ $-\% 20$ High\%20Strength.pdf

13. Soadya K.A., Mellor B.G., Shackletonb J., Morrisc A., Reeda P.A.S., The effect of shot peening on notched low cycle fatigue. Materials Science and Engineering: A, 528, 2011, 8579-8588.

14. Stegliński M., Byczkowska P., Sawicki J., Kaczmarek Ł., Januszewicz B., Klich M. Synergy of the plastic treatment hpt and shot peening in aluminium alloy Al-Mg-Mn-Sc-Zr, Archives of Metallurgy and Materials, 61 (2B), 2016, 1135-1142. 